\title{
À QUEIMA-ROUPA: rebaixamento, prazer e desejo em casos de violência policial contra travestis
}

SHOT AT CLOSE RANGE: demeaning, pleasure, and desire in cases of police violence against travestis

\section{Roberto Efrem Filho}

\section{(2) OpenEdition}

Edição electrónica

URL: https://journals.openedition.org/aa/8904

DOI: 10.4000/aa.8904

ISSN: 2357-738X

\section{Editora}

Programa de Pós-Graduação em Antropologia Social (UnB)

Edição impressa

Paginação: $30-48$

ISSN: 0102-4302

\section{Refêrencia eletrónica}

Roberto Efrem Filho, «À QUEIMA-ROUPA: rebaixamento, prazer e desejo em casos de violência policial contra travestis», Anuário Antropológico [Online], v.46 n.3 | 2021, posto online no dia 28 setembro 2021 , consultado o 05 outubro 2021. URL: http://journals.openedition.org/aa/8904 ; DOI: https://doi.org/ 10.4000/aa.8904

\section{(c) (i) (9)}

Anuário Antropológico is licensed under a Creative Commons Atribuição-Uso Não-Comercial-Proibição de realização de Obras Derivadas 4.0 International. 


\section{Anuário Antropológico}

v.46 n.3 | 2021

2021/v.46 n.3

\section{À queima-roupa: rebaixamento, prazer e desejo em casos de violência policial contra travestis}

Shot at close range: demeaning, pleasure, and desire in cases of police violen-

ce against travesties

\section{Roberto Efrem Filho}

\section{OpenEdition}

Journals

\section{Edição electrônica}

URL: http://journals.openedition.org/aa/8904

DOI: $10.4000 / a a .8904$

ISSN: $2357-738 X$

\section{Editora}

Programa de Pós-Graduação em Antropologia Social (UnB)

\section{Referência eletrônica}

Roberto Efrem Filho, «À queima-roupa: rebaixamento, prazer e desejo em casos de violência policial contra travestis», Anuário Antropológico [Online], v.46 n.3 | 2021. URL: http://journals.openedition.org/ aa/8904 ; DOI: https://doi.org/10.4000/aa.8904

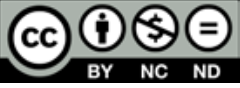

Anuário Antropológico is licensed under a Creative Commons. Atribuição-SemDerivações-SemDerivados CC BY-NC-ND 


\title{
anuário antropológico
}

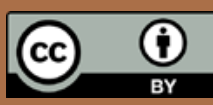

v. $46 \cdot n^{0} 3 \cdot$ setembro-dezembro $\cdot 2021.3$

\section{À queima-roupa: rebaixamento, prazer e desejo em casos de violência policial contra travestis}

\author{
SHOT AT CLOSE RANGE: demeaning, pleasure, and desire in cases of police violence \\ against travesties \\ DOI: https://doi.org/10.4000/aa.8904
}

\begin{abstract}
Roberto Efrem Filho
Universidade Federal da Paraíba, Centro de Ciências Jurídicas, Departamento de Ciências Jurídicas, Santa Rita, PB - Brasil

Professor do Departamento de Ciências Jurídicas da Universidade Federal da Paraíba - UFPB (Santa Rita, PB) e do Programa de Pós-Graduação em Antropologia da UFPE (Recife, PE). É doutor em Ciências Sociais pela Unicamp e concluiu mestrado e graduação em Direito junto à UFPE.
\end{abstract}

Neste artigo, eu procuro analisar como noções de humilhação, nojo e desprezo informam "imagens de brutalidade" acerca de mortes de LGBT reivindicadas como crimes de ódio ou LGBTfobia. Valendo-me de dados colhidos durante o acompanhamento de atividades do movimento LGBTI+ na Paraíba, entre 2012 e 2016, de entrevistas em profundidade com seus militantes e do acesso a autos judiciais relativos àquelas mortes, centro atenção especialmente nas narrativas em torno: a) de uma cena de tentativa de homicídio, provocada por um policial militar que, numa rua do centro de João Pessoa, disparou à queima-roupa contra uma travesti que se prostituía e recusou sua cantada; e b) do caso do "serial killer de travestis", um policial militar acusado de cinco assassinatos numa cidade do sertão paraibano. Com isso, intenciono principalmente notar a relevância de práticas de rebaixamento para a configuração daquilo que é tomado como brutal, inclusive a violência policial. Busco sobretudo compreender a sexualização narrativa daquele que rebaixa, humilha, enoja-se e despreza e cujo ato de violentar ou matar é identificado como um gesto de prazer ou remete à suspeita de um desejo.
In this paper, I seek to analyze how notions of humiliation, disgust and contempt inform "images of brutality" regarding LGBT deaths claimed to have been the result of hate crimes or LGBTphobia. Based on data collected during the monitoring of the LGBTI+ movement's activities in Paraíba between 2012 and 2016, in-depth interviews with its activists, and access to judicial proceedings related to those deaths, I focus especially on the narratives around: a) a scene of attempted murder provoked by a military police officer who, in a street downtown João Pessoa, shot a travesti at close range, one who worked as a prostitute and refused his flirt; and b) the case of the "serial killer of travestis", a military police officer accused of five murders in a town in the countryside of Paraíba. Thereby, my main purpose is to discuss the relevance of demeaning practices for the configuration of what is taken as brutal, including police violence. Above all, I seek to understand the narrative sexualization of the one who demeans, humiliates, feels disgusted and despises others, and whose act of raping or killing is identified as a gesture of pleasure or raises questions about desire.

Keywords: Violence. Demeaning. Sexuality. Pleasure. Desire. 


\section{Notas de campo}

[23 de maio de 2017, auditório da central de polícia, Geisel, João Pessoa - PB]. "Professor, um caso assim deve ser muito interessante de analisar, não? O sujeito mata porque não se aceita. É terrível. É a homofobia internalizada" - disse-me Fabiola ${ }^{1}$ ainda enquanto nos levantávamos das cadeiras, mal o evento terminara. Fabiola integrava a equipe da Secretaria de Estado da Mulher e da Diversidade Humana (SEMDH) do Governo da Paraíba e havia participado do processo de organização daquele seminário, para o qual eu fui convidado na condição de professor universitário, ao lado de militantes de movimentos sociais e agentes governamentais. O seminário intitulado "Vítimas LGBT no inquérito policial" resultava então do esforço conjunto de agentes da SEMDH e da Secretaria de Estado de Segurança e Defesa Social (SEDS) e se propunha à exposição de dados estatísticos acerca de mortes de LGBT ${ }^{2}$ ocorridas em 2016 na Paraíba e ao estudo de alguns casos de violência letal tidos como emblemáticos e apresentados, na ocasião, pelos próprios delegados de polícia que conduziram as investigações. O último caso estudado, ao qual Fabiola se remetia em seu comentário no final do evento, tornara-se amplamente conhecido como o "caso do serial killer de travestis" e compreendia cinco homicídios e uma tentativa de homicídio que, segundo o delegado, teriam sido cometidos pelo policial militar Renato Humberto de França, um serial killer cuja "assinatura" consistiria no desferimento de um tiro na base do crânio de suas vítimas, prostitutas abordadas por ele à noite no centro da cidade de Carcarás, no sertão paraibano, e levadas na garupa de sua motocicleta às proximidades do Campo da Bagaceira, um local próximo onde aconteciam ou aconteceriam os programas. Para o delegado, o "caso do serial killer de travestis" referir-se-ia a crimes de ódio, o que se comprovaria pelo modus operandi das mortes e, inclusive, pela seguinte frase, pronunciada por Renato Humberto e escutada por Edmundo, a única vítima sobrevivente, após sofrer três disparos, um deles na cabeça: "agora que eu acabei com você e com os outros quatro, vou acabar com o restante das raparigas, das sapatonas e dos viados".

\section{Apresentação}

Tomado como um emblema de homofobia pelos agentes de Estado presentes àquele seminário de 23 de maio de 2017, o "caso do serial killer de travestis" foi também assim compreendido por militantes do movimento LGBTI+ paraibano já em 2011, quando duas das vítimas de Carcarás preencheram a lista de nomes do relatório anual sobre "crimes relacionados ao ódio contra homossexuais no estado da Paraíba", então elaborado por integrantes do Movimento do Espírito Lilás (MEL) através de consultas à imprensa e a delegacias de polícia. Naquele relatório de 2011, portanto, as mortes de Lígia e Xaxá - conforme o delegado, a quarta e a quinta vítimas fatais do serial killer - somavam-se a 19 outras mortes para compor o que chamei, num primeiro tratamento analítico desse material, de "imagens de brutalidade" (Efrem Filho, 2016).
1 Neste artigo, alguns nomes próprios foram ficcionalizados e estão em itálico. Mantive também em itálico estrangeirismos, categorias êmicas e expressões sob rasura, que podem ser objeto de problematização, como homofobia e serial killer. Estão entre aspas as citações diretas e categorias êmicas ou sob rasura mais longas, como "o caso do serial killer de travestis".

2 LGBT, LGBTI+, LGBTQI+ e suas variantes são siglas atinentes a lésbicas, gays, bissexuais, travestis, mulheres trans, homens trans, queers, não-bináries, intersexuais e outras expressões ou identidades de gênero e sexuais. Aqui, uso a sigla LGBT em respeito ao que consta no corpus de pesquisa. Para discussões a respeito das disputas e políticas em torno das siglas e de suas “identidades”, ver: Facchini (2005) e Aguião (2016). 
Estas imagens de brutalidade consistem em narrativas de violência que costumam ser mobilizadas e visibilizadas em meio às estratégias para produção de reconhecimento público das vulnerabilidades experienciadas por LGBT e da urgência de políticas de enfrentamento à LGBTfobia ${ }^{3}$. Concernem a corpos marcados por atos de violência física cujos excessos - a cabeça esmagada, o rosto desfigurado, o estupro anterior ou a violação posterior ao assassinato, as dezenas de facadas, o golpe de faca peixeira no ânus da vítima - oportunizariam, a militantes do movimento LGBTI+ e certos agentes de Estado, a sua identificação como crimes de ódio. Desse modo, os tiros desferidos contra Lígia e Xaxá agregam-se, naquele relatório anual e nos processos de denúncia e reivindicação de direitos nele implicados, a diferentes atos de violência física que, brutalizados narrativamente, consubstanciariam o ódio e, assim, a homofobia a serem combatidos ${ }^{4}$.É que incidindo sobre o corpo, tais imagens de brutalidade saturam-se de sentidos emocionais. Levam o corpo ao limite, exposto fraturado, retalhado ou esmagado, para torná-lo inteligível e apreensível, como diria Butler (2010). Entretanto, a brutalização narrativa do corpo sobre o qual anteriormente operou o gesto entendido como violento permite ao corpo e a seus cortes a incitação e a materialização de emoções, do que decorre a possibilidade de enunciação do ódio, supostamente sentido pelo sujeito que haveria operado a violência física. Este ódio funciona narrativamente, então, como justificativa ou causa para o ato de violência e, sobretudo, para seus excessos, o que acaba pressupondo a assunção das noções de repulsa, desprezo ou nojo germinadas ao ódio, algo semelhante àquilo que Maria Claudia Coelho (2010) denominou, em estreito diálogo com Miller (1997), de complexo emocional.O corpo brutalizado alude, portanto, à existência de práticas de rebaixamento e hierarquização fundadas, por exemplo, num complexo emocional ódio-repulsa-desprezo-nojo atribuível a um determinado algoz, como o "serial killer de travestis", uma persona narrativamente capaz tanto de catalisar essas emoções para a obliteração de cinco vidas em Carcarás quanto da autoria daquela frase, quase novelesca, pronunciada diante do corpo alvejado três vezes, uma delas na cabeça, de um Edmundo aparentemente morto: "agora que eu acabei com você e com os outros quatro, vou acabar com o restante das raparigas, das sapatonas e dos

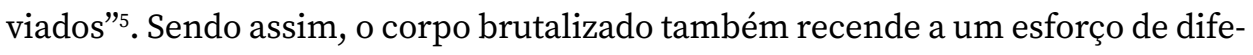
renciação do algoz, aquela persona que amalgama emoção e ato excessivos e cuja denunciação procura provocar novos complexos emocionais em quem se depara com sua imagem de brutalidade e indelevelmente aturde-se, choca-se, duvida ou mesmo enraivece-se - como aconteceu comigo em inúmeros momentos desde que passei a investigar narrativas de violência.

Neste artigo, volto-me a imagens de brutalidade informadas por noções de repulsa, humilhação, nojo e desprezo, reivindicadas como crimes de ódio, homofobia ou transfobia. Para tanto, centro atenção especialmente nas narrativas em torno: a) de uma cena de tentativa de homicídio, provocada por um policial militar que, numa rua anoitecida do centro de João Pessoa, disparou à queima-roupa contra uma travesti (ou mulher trans) ${ }^{6}$ que se prostituía e recusou sua cantada; e b) do mencionado "caso do serial killer de travestis", um policial militar acusado, como dito,
3 LGBTfobia, transfobia, homofobia etc. são aqui tomadas como categorias êmicas frequentes no repertório de militantes do movimento LGBT e dos sujeitos que orbitam em seu "campo" ou sua "arena" (Facchini, 2005). Genericamente, tais expressões se referem a discriminações, preconceitos e violências vivenciados por LGBTI+. Compreendo-as, no entanto, como "chaves de inteligibilidade" que iluminam modos como gênero e sexualidade operam em experiências de vulnerabilização, sendo reciprocamente constituídas por relações de classe, geração, racialização e territoriais (Efrem Filho, 2017b).

4 No corpus de pesquisa analisado neste artigo, a expressão homofobia é usualmente empregada para aludir a violências sofridas por LGBTI+ indistintamente. Hoje em dia, contudo, casos assim seriam provavelmente descritos como transfóbicos.

5 Esta frase, apresentada pelo delegado de polícia durante o seminário de 23 de maio de 2017, também consta no texto da denúncia que inaugurou o processo judicial criminal a respeito da morte de Suzanita.

6 Lua refere-se a si mesma ora como mulher trans ora como travesti. Na entrevista que me concedeu em 20 de julho de 2013, ela se valeu bastante mais da palavra travesti e me falou o seguinte sobre esta questão: “(...) eu falo travesti porque tou muito acostumada com esse nome, então desconstruir isso vai ser um processo ainda. Todas nós somos mulheres trans". Neste texto, opto preponderantemente pela palavra que ela emprega com maior frequência. Para discussões acerca dos conflitos e agenciamentos em torno das categorias travesti e transexual, ver: Leite Jr., 2011; Barbosa, 2013; e Carvalho, 2018. 
de cinco assassinatos e uma tentativa de assassinato cometidos numa cidade do sertão paraibano. Com isso, intenciono notar possíveis correlações entre violência, rebaixamento e sexualidade para a configuração daquilo que é tomado como brutal, inclusive a violência policial. Busco sobretudo percorrer a sexualização narrativa daquele que rebaixa, humilha, repudia, enoja-se e despreza e cujo ato de violentar ou matar é identificado como um gesto de prazer ou remete à suspeita de um desejo, como se deu naquele comentário de Fabíola ao final do seminário no auditório da central de polícia: "O sujeito mata porque não se aceita. É terrível. É a homofobia internalizada”.

As narrativas de violência aqui analisadas derivam principalmente do corpus de minha pesquisa de doutorado (Efrem Filho, 2017a), que contou com o acompanhamento, entre 2012 e 2016, de atividades do movimento LGBTI+ na Paraíba; entrevistas em profundidade com seus militantes; e o acesso a autos de inquéritos policiais e processos judiciais relativos às mortes reivindicadas como crimes de ódios. As narrativas em torno do "caso do serial killer de travestis", contudo, compõem-se também por documentos públicos, matérias jornalísticas, entrevistas televisivas e radiofônicas e pelos autos de um processo judicial, todos colhidos durante projeto de pesquisa que coordenei posteriormente junto à Universidade Federal da Paraíba, entre os anos de 2017 e $2019^{7}$.

A diversidade desse corpus de pesquisa, em especial no que concerne ao caso do serial killer, possui dois motivos principais. O primeiro deles, de ordem prática, é o de que somente foi possível acessar os autos judiciais relativos a uma das seis hipotéticas vítimas do serial killer de Carcarás, Suzanita, visto que os demais processos judiciais correram sob segredo de justiça ${ }^{8}$. Esta limitação acarretou algumas dificuldades para a análise do caso e a compreensão dos seus conflitos internos, notadamente das teses de acusação e defesa, o que demandou a extensão dos documentos pesquisados a entrevistas, matérias jornalísticas e outros documentos públicos. Dá-se que, como bem notou Cilmara Veiga (2018), o "ritmo dos papéis" em processos judiciais relativos a um "crime em série" possui dinâmicas peculiares, em que "o ritmo acaba por ser potencializado pela série" e se dá "uma espécie de mimese" entre a forma de matar, repetida na execução dos crimes, e os documentos que se repetem nos diferentes processos judiciais (Veiga, 2018, p. 79; p. 86). Embora os autos judiciais acerca da morte de Suzanita - segundo o delegado, a terceira vítima fatal do serial killer - reproduzam documentos e elementos narrativos dos outros processos judiciais, como a citada frase que Edmundo ouvira após ser baleado três vezes, esses autos padecem da ausência de documentos e elementos que parecem haver sido abordados nos outros autos, nas apurações das mortes de Lígia e Xaxá, por exemplo.

Por sua vez, o segundo motivo, agora de ordem metodológica, remete à relevância analítica desses diversos documentos para o engendramento das imagens de brutalidade e das narrativas de violência de que me ocupo neste texto. Seguindo Letícia Ferreira (2013), observo que documentos produzem e rearranjam relações, consistindo em espaços de tomada de posição e não em meras representações de fatos e sujeitos preexistentes. Pelo contrário, como Lucas Freire (2016) percebeu,
7 O projeto de pesquisa intitulado "Disputas acerca da vítima: conflitos e materializações nas narrativas judiciais sobre mortes de LGBT", aprovado junto ao DCJ/UFPB e registrado sob os códigos PIH9380-2017 e PVH820-2018, contou com a participação de sete estudantes de graduação e foi financiado com duas bolsas de iniciação científica do CNPQ. Para resultados parciais desse projeto, ver: Efrem Filho; Gomes, 2020; Efrem Filho, Souza Júnior, Leite, 2020.

8 O segredo de justiça está previsto no artigo 155 do Código de Processo Civil e deve-se dar, por exemplo, quando "o exigir o interesse público". Imagino que o interesse público no "caso do serial killer de travestis" concirna ao fato de que o investigado era policial. Não resta claro, contudo, o porquê de os autos judiciais relativos ao homicídio de Suzanita não correrem igualmente sob segredo. 
documentos podem conferir realidade e materialidade a sujeitos, que apenas se tornam reconhecíveis e aptos a acessar direitos a partir de determinados papeis. Isto adquire contornos específicos e uma gravidade própria quando os documentos em questão consistem em autos judiciais. É que, como notou Mariza Corrêa (1983) num trabalho fundamental sobre o tema, nos processos judiciais "os atos deixam de ter importância em si mesmos e passam a ser importantes em função dos autos, das teses que serão debatidas publicamente por acusação e defesa" (1983, p. 24).

Dessa maneira, importa menos se o policial Renato Humberto de França de fato disse ou não aquela frase que Edmundo ouviu ou não, pois importam mais as formas como essa frase é montada e articulada nos autos em meio aos conflitos ali existentes, sobremaneira quanto à figuração da personagem do algoz e ao adensamento das conexões entre as diferentes mortes - "agora que eu acabei com você e com os outros quatro..." -, conexões estas que oportunizam a caracterização de um serial killer. De modo semelhante, importa menos se Renato Humberto sentia realmente ódio, repulsa, desprezo ou nojo por homossexuais e travestis, e mais como esses sentidos emocionais são a ele atribuídos para a conflagração narrativa de uma "causa" para os cinco crimes de homicídio consumado e a sua tentativa contra Edmundo. Este atrelamento entre emoções, atos e algoz garante a fabricação da "coerência", como a chamou Larissa Nadai (2016), capaz de subsidiar "nexos de causalidade", "indícios suficientes de autoria" e os processos políticos de denunciação e reivindicação por direitos e justiça em que as imagens de brutalidade têm lugar.

\section{Notas de campo}

[20 de julho de 2013, Centro Estadual de Referência dos Direitos de LGBT, Centro, João Pessoa - PB]. "Eu já fui vítima de policial diversas vezes. A última vez em que eu fui vítima de policial, tomei dois tiros, que eu tenho cicatriz na minha perna até hoje. Então assim, não tenho nada de bom pra falar de polícia” - Lua dizia e apontava os locais das pernas em que se situavam as cicatrizes. Sentada diante de mim numa das salas do Espaço LGBT de João Pessoa, o gravador entre nós, Lua rememorava violências que viveu ou presenciou durante os cinco anos em que se dedicou à prostituição de rua no centro da capital paraibana, "dores e prazeres" - ela me conta, "mais dores do que prazeres" - ela explica. Um desses episódios de violência, talvez o fisicamente mais grave, iniciou-se com uma cantada. Lua já vinha deixando as ruas àquela época, mantinha poucos clientes antigos que a procuravam quando interessados, integrava-se cada vez mais às atividades do movimento LGBTI+ que, com o tempo, acabariam rendendo-lhe uma nova profissionalização. Naquela noite, havia decidido ir à seresta promovida pela dona de um bar localizado no bairro onde morava. Comprava cigarros quando o policial fardado a abordou pelas costas, distanciando-se das duas mulheres que $o$ acompanhavam na mesa do bar a que sentava: "ele chegou pra mim e disse que ia deixar as mulheres em casa, que uma delas era namorada dele, que ia deixar em 
casa e, quando voltasse, eu ia fazer sexo oral nele, que ia ejacular na minha boca, que ia fazer aquilo e tal". Lua, no entanto, não gostou da abordagem, "da maneira que ele deu a cantada". Sentiu-se ofendida, "me deixou péssima", e reagiu: "tome vergonha na sua cara, vá ficar com a sua namorada, sua mulher ali, por sinal, muito bonita, e você deixa a mulher na mesa e me dá uma cantada dessa natureza". Chamou-o de "safado" e se afastou. O policial saiu, mas logo retornou. Segundo Lua, "ele cegou". Com força, arrastou-a para trás do bar, "começou a rasgar minha roupa, eu comecei a gritar, ele colocou um cano da arma no buraco do meu nariz, queria colocar na minha boca, passou por aqui e foi descendo, esfregou no meu peito ainda. Aí, quando chegou na minha perna, deu um tiro à queima roupa". Impactado com o que Lua me contava sobre aquele episódio, eu a questionei se o tal policial havia atirado propositadamente. Ela confirmou. Explicou que o policial "escolheu o canto pra atirar, fez todo um terrorismo comigo". O homem fardado passou a arma pelo seu rosto, "botou pra mim cheirar, colocou no meu nariz", tentou introduzir o cano da arma em sua boca, "até cortou um pouco a minha boca", e então desceu a arma, "e daí ele foi descendo essa arma, descendo", arrastando-a pelo corpo de Lua até chegar às suas coxas, "e quando chegou na perna, disparou no canto e disparou no outro". Após os dois tiros, o policial militar se dirigiu ao seu carro, estacionou-o numa esquina próxima e voltou-se mais uma vez a Lua, municiando a arma e novamente atirando. Nesse instante, uma moça que havia assistido a tudo correu e se jogou sobre Lua, "ela ficou deitada em cima de mim, eu só lembro de ela ter ficado no meu ouvido "não se mexe que ele tá atirando"”.

Assim que os tiros cessaram, a moça levou Lua para dentro do banheiro do bar, notou a quantidade de sangue, amarrou com uma blusa a perna que sangrava e deixou o local. O policial militar, que aparentemente havia retornado ao carro para municiar a arma, ainda desferiu mais três tiros contra a porta do banheiro, mas não conseguiu atingir Lua. Quando, algum tempo depois, resolveu sair do banheiro, Lua não encontrou mais ninguém no bar.

\section{Violência policial, Estado e degeneração}

A violência policial atravessa o cotidiano de profissionais do sexo, a ponto de o seu enfrentamento ser central às pautas dos movimentos de prostitutas (Olivar, 2012; Mello, 2016). De regra, as ações policiais sobre a prostituição de rua que ensejam a nomeação de "violência" concernem à gestão de territórios. Remetem, por exemplo, às batidas policiais, de que tratou Claudia Fonseca (1996), que retiravam prostitutas das ruas de Porto Alegre para levá-las a delegacias onde elas, mesmo cientes de não haver cometido qualquer crime, resolviam pagar o valor da fiança para evitar a tortuosa burocracia que as fazia perder tempo e clientes. Nas lembranças de Lua sobre suas andanças na noite, por sua vez, tais ações policiais remetem a violações de direitos. "Naquela época, eu era menor de idade e, mesmo assim, eu sofria muitas violações de direitos por parte dos policiais".

Lua conta que ela e outras monas eram postas na frente de viaturas com faróis acesos em luz alta "pra gente ficar com a vista meio embaraçada", depois jogadas 
dentro do camburão apenas para serem levadas à delegacia, "só pra a gente passar por constrangimento, de ficar aquela coisa de tá jogando pra um, jogando pra outro, olha tua irmã aí, isso é tua irmã”. Segundo Lua, essas abordagens policiais por vezes respondiam a interesses de comerciantes locais, do centro da cidade, que pretendiam afastar a prostituição de certas regiões. "Existia muito a questão da pegação na rua mesmo, e ficava vestígio de preservativo, vestígio de alguma coisa no amanhecer do dia, as pessoas ficavam muito insatisfeitas com isso". Noutras ocasiões, as ações de policiais vinculavam-se a processos de criminalização mais intensos, que atrelavam a prostituição a práticas de crimes patrimoniais e ao mercado e ao consumo de drogas ilícitas.

Nas memórias de Lua, portanto, agentes de Estado incidiam na prostituição de rua através de uma gestão do território urbano que permitia a conformação de corpos manobráveis, coercíveis e deslocáveis, perfeitos em experiências muito precárias de classe e em relações desiguais de gênero, sexualidade e geração - "eu era menor de idade", afinal. De certo, seguindo o que Lua me falou, essa conformação de corpos dependia da tomada da atividade de prostituição como produtora de um cenário de "degeneração sexual", diria McClintock (2010), do que se infere a insatisfação com os vestígios de pegações e preservativos. Contudo, esses corpos degenerados tornavam-se mais disponíveis à intervenção policial à medida que mais próximos dos citados processos de criminalização, daquilo que Michel Misse (2010) chamou de "sujeição criminal". Nesse sentido, a violência policial contra prostitutas assemelha-se às práticas de violência policial cometidas corriqueiramente nas periferias dos grandes centros urbanos brasileiros, parte da constituição do problema da "violência urbana" como justificativa inescusável para o exercício do controle sobre sujeitos, corpos e territórios profundamente racializados.

A narrativa de Lua acerca daquela noite na seresta em João Pessoa e parte importante das narrativas judiciais sobre as vítimas do serial killer de travestis de Carcarás convergem, entretanto, para uma associação ainda mais estreita entre práticas de prostituição e violência policial. Aqui, policiais não atuam exteriormente sobre um cenário de degeneração sexual e delinquenciação: Renato Humberto de França e o policial militar que, fardado, cantou Lua no bar imiscuem-se nesse cenário. Numa entrevista concedida a um canal de TV local da cidade de Carcarás quando da prisão de Renato Humberto, em fevereiro de 2012, o delegado de polícia contou que somente chegou aos suspeitos das mortes depois da realização de um "levantamento junto aos travestis" com o intuito de distinguir os "frequentadores daquela região". Renato Humberto era um desses frequentadores, um "frequentador assíduo daquele local", uma "pessoa conhecida dos homossexuais que ali faziam seus programas", como salientou o promotor de justiça na denúncia do processo judicial acerca da morte de Suzanita. Por sua vez, segundo o que a dona do bar contaria a Lua no dia seguinte ao episódio, aquele policial era afamado e bastante conhecido dela e de seus clientes do bar, "ele tinha uma fama de que quando ele bebia era agressivo, ele dava tiro pra cima, tipo assim, 'eu sou policial, eu mando na rua"”.
9 Durante a entrevista, 0 delegado se refere à travesti no masculino e a apresenta pelo seu nome masculino de registro civil, prática esta que se reproduz nos autos judiciais e nas matérias jornalísticas sobre o "caso". 
Nas narrativas de que me valho sobre esses dois casos de violência, portanto, policiais parecem exercer sexualidade, incidir sexualmente sobre territórios e corpos, de modo que a sexualidade não emerge como uma alteridade a ser controlada - as prostitutas e seus programas nas noites de João Pessoa e Carcarás -, mas consiste em vínculo precípuo ou suspeito entre as figuras do algoz e da vítima. Isto, importa notar, não aparta o adjetivo "policial” do substantivo "violência". A violência narrada por Lua não deixa de ser violência policial porque aquele homem fardado não se encontra formalmente no exercício de suas funções militares. Pelo contrário, Lua somente mencionou o episódio da seresta durante a entrevista, após uma pergunta minha sobre a participação de policiais no processo de criminalização da prostituição de rua. "Os policiais até hoje são cruéis. Eu não tenho uma boa referência pra dar por parte dos policiais, porque todas as minhas vivências com eles foram negativas, (...) desde a solicitação de serviço até as abordagens na rua, todas foram desumanas". O episódio da seresta, assim, soma-se às demais experiências de Lua com policiais. Embora represente mais evidentemente uma imagem de brutalidade, não se destaca de suas outras experiências, leva-as ao extremo.

Minha percepção das imbricações entre práticas sexuais e violência policial, todavia, adveio da leitura dos trabalhos de Breno Marques de Mello (2019; 2016). A partir de uma pesquisa etnográfica realizada junto à Associação das Prostitutas da Paraíba, Mello acessou narrativas de prostitutas cujas relações com policiais - clientes mais ou menos próximos, namorados e maridos - submetiam-nas a situações de violência, como espancamentos e estupros, mas também a práticas sexuais inicialmente consentidas e que se tornavam violentas em seu transcurso, com o uso de fardas, armas, algemas, coturnos, cassetetes etc. Mello (2019; 2016) compreendeu tais instrumentos apresentados nessas cenas como signos de poder alusivos a uma estética de Estado que o impediam de separar, por exemplo, a figura do policial da figura do cliente (policial) que saca uma arma de fogo em meio a uma transa e a aponta para a cabeça da prostituta.

Dos autos judiciais e documentos públicos disponíveis acerca do "caso do serial killer de travestis", não se tem notícia se as prostitutas e os demais "frequentadores daquela região" identificavam ou não Renato Humberto de França como policial militar - o que não seria tão improvável, considerando a sua alegada assiduidade e as dinâmicas de uma cidade do porte de Carcarás $^{10}$. Nada se diz nos documentos sobre a possibilidade de ser policial ter facilitado ou não o acesso de Renato Humberto àquelas pessoas, por exemplo. No entanto, a aparição narrativa da arma de Renato Humberto nos autos do processo judicial acerca da morte de Suzanita provoca conexões difíceis de escusar entre o ofício policial e o ato de violência. Na denúncia, afinal, o promotor de justiça ressalta como prova de indício de autoria que o Laudo do Exame de Confronto Balístico apontara que "os projéteis questionados saíram da arma de fogo apreendida em poder do denunciado". Mas conexões assim também se dão com a decisão pelo sigilo ou segredo de justiça, requerido pelo delegado de polícia em razão de um dos suspeitos ser policial, como explicou no seminário de 23 de maio de 2017, sugerindo então que o ofício
10 Carcarás possui aproximadamente 108 mil habitantes. 
policial poderia dificultar as investigações e oportunizar mais mortes.

Por sua vez, a cena do policial militar fardado arrastando Lua para trás do bar, rasgando sua roupa e impondo-lhe uma arma contra o rosto após uma cantada recusada impregna-se dos signos de poder de que fala Breno Mello (2019). De pronto, há a farda. "Veja só, um policial fardado, num seresta, tomando cerveja, armado, com a esposa. (...) ele já tava errado a partir do momento em que ele sentou num mesa pra tomar cerveja fardado, com a farda da polícia e com a arma da polícia também”. No que Lua me diz, a farda incita efeitos de poder, os quais poderiam inclusive haver participado da oportunidade da cantada e daquilo que tornou a sua recusa algo tão inadmissível. Mas há mais. Há o que se falava a seu respeito, a fama de homem que bebe e se torna agressivo, "ele dava tiro pra cima, tipo assim, 'eu sou policial, eu mando na rua”'. Há, em outras palavras, gestão territorial implicada em estridentes performances de masculinidade. Há, ademais, a crença em sua impunidade, parte dos processos de Estado que protegem alguns de seus agentes.

Aquelas narrativas judiciais sobre o serial killer e a narrativa de Lua sobre o policial militar que a abordou na seresta enunciam experiências de violência policial cujo reconhecimento requer sua apreensão "em ato". Trata-se, sendo assim, de tomar o fazer policial em sua performatividade, num movimento de análise análogo àquele empreendido por Vianna e Lowenkron (2017) quando de sua compreensão do "duplo fazer do gênero e do Estado". Os gestos de erguer a arma e desferir o tiro que atingiu a base do crânio de Suzanita, tais quais os gestos de arrastar Lua, rasgar suas roupas e brandir uma arma contra o seu rosto exsurgem narrativamente como fazer estatal - e isto, como dito, não apenas porque as armas em questão pertencem à polícia militar. Processos de Estado se dão intensamente às suas margens, no esforço de constituição de suas fronteiras, nos interstícios do que se constitui discursivamente como ausência ou falta de Estado. Processos de Estado se depreendem inclusive em meio ao que se produz como oposto ao Estado, no engendramento de corpos, territórios e sujeitos delinquenciais e degenerados, passíveis de controle (Efrem Filho, 2017b). Faz-se violência policial e "de Estado" ao tempo que se fazem políticas e práticas sexuais. Estas se materializam em faróis acesos contra um grupo de travestis detidas na noite de João Pessoa; ou numa cantada malsucedida cuja recusa de uma travesti não se pode admitir.

\section{Violência, rebaixamento e prazer}

Se as narrativas de violência a que me dedico neste texto são densamente significadas como de "violência policial", é possível argumentar que parte do que as constitui como sendo "de violência" se relaciona intimamente a uma compreensão do fazer policial como produtor de hierarquia, rebaixamento e humilhação. Isto, de certo, apresenta-se mais contundente nas histórias de Lua sobre seus contatos com policiais, as vezes em que ela e as demais meninas eram jogadas num camburão em direção à delegacia "só pra a gente passar por constrangimento, de ficar aquela coisa de tá jogando pra um, jogando pra outro, olha tua irmã aí, isso é tua irmã”. À exceção do que aconteceu naquela noite na seresta, Lua não me relatou 
episódios de agressão física provocados por policiais. A violência que ela agrega a eles de modo amplo, "os policiais até hoje são cruéis", resulta narrativamente portanto de experiências de constrangimento, desrespeito e humilhação, as quais, segundo Everton Rangel (2020, p. 184), podem operar tanto interpessoalmente quanto como tecnologias de governo.

Não pretendo com isso sugerir que práticas de hierarquização, rebaixamento e humilhação sinonimizam violência. Como uma relevante literatura vem salientando, a constituição da violência requer investimentos morais que assim a concebam (Corrêa, 1983; Gregori, 1993; Simião, 2006; Cardoso de Oliveira, 2008). Humilhações, por sua vez, nem sempre são denotadas como violentas por quem as pratica, a elas se submete ou é submetido (Díaz-Benítez, 2019; 2015). Ao ressaltar a importância de práticas de hierarquização, rebaixamento e humilhação nas narrativas de Lua acerca da violência policial, eu pretendo, seguindo Everton Rangel, discernir contextos narrativos nos quais "os dois fenômenos em questão existem em relação de dependência e demandam formas de pensar gênero" (2020, p. 172). Isto porque a citada tomada do fazer policial como produtor de hierarquia, rebaixamento e humilhação acaba por articular-se a uma figuração estatal antropomorfizada e masculinizada, materializável nos policiais de que fala Lua, algo parecido ao que Vianna e Farias (2011) perceberam nas denúncias e acusações promovidas por mães e familiares de vítimas de violência de Estado.

Em outras palavras, as narrativas de Lua assinalam a presença de algo "de Estado" e reciprocamente de gênero no que enseja hierarquia, rebaixamento, humilhação e, sendo assim, aquilo que ela demonstra entender como violência. "Nós (policiais) somos nós e pronto, e acabou-se. E sempre viam a gente como minoria, como lixo humano, como...”. Os faróis acesos, a traseira do camburão, as chacotas na delegacia - "olha tua irmã aí, isso é tua irmã" - seriam performances de masculinidade animadas por e animadoras de processos de produção de autoridade e competência não muito distantes do "eu sou policial, eu mando na rua" que $L u a$ atribui ao policial militar que a agrediu durante a seresta. Desse modo, a associação entre práticas de Estado, performances de gênero e práticas de rebaixamento participa decisivamente do que é apreendido como violento, de acordo com as narrativas neste texto analisadas. Essas narrativas de violência, entretanto, recrudescem-se em imagens de brutalidade à proporção que se aproximam da sexualidade, das práticas e políticas sexuais.

É que a associação entre violência e sexualidade toca no que Maria Filomena Gregori (2008) chamou de "limites da sexualidade", um espaço fronteiriço em que habitam norma e transgressão, consentimento e abuso, prazer e dor, a tensa relação entre prazer e perigo. Esses limites são tensionados, por exemplo, quando dos conflitos em torno da existência de sujeitos que vivenciam a sexualidade através da ritualização da dor e do sofrimento, como acontece com os praticantes do sadomasoquismo erótico e do BDSM ${ }^{11}$ a que Gregori (2016) e Regina Facchini (2008) voltaram suas atenções. Tais conflitos podem compreender a ratificação de moralidades e a mobilização de pânicos sexuais que identificam a "comunidade" de adeptos de certas práticas sexuais como degenerada e violenta, passível então
11 BDSM é sigla para bondage, disciplina, dominação, submissão, sadismo e masoquismo. 
de criminalização. Não à toa, segundo Facchini e Machado (2013) apontam, as narrativas acerca de si dos membros dessa "comunidade" enfatizam noções de consentimento, consensualidade, segurança, liberdade de escolha e repúdio à agressão com vistas a sua própria legitimação e a de seus prazeres, cuja linguagem remete à erotização de hierarquias. Outro exemplo de tensionamento dos tais limites da sexualidade pode ser encontrado nas práticas extremas de pornô bizarro de que tratam os trabalhos de María Elvira Díaz-Benítez (2012). De acordo com Díaz-Benítez, a pornografia do sexo com animais costuma ser alvo de críticas relacionadas à suposta ausência de consentimento por parte dos animais, o que leva a acusações de ilegalidade com que os membros dessas redes de pornô precisam haver-se.

Dá-se que, como notou Laura Lowenkron (2015), o consentimento ocupa centralidade nas definições do que é legal e legítimo acerca dos comportamentos sexuais. Atine a uma "economia moral do uso dos prazeres" que se propõe ao controle e à condenação da violência e da violação de direitos, ao invés da imoralidade (Lowenkron, 2015, p. 226). Compõe assim, complementarmente à noção de vulnerabilidade, os regimes jurídicos atuais de regulação das sexualidades e do que se compreende por violência. Por isso, os exemplos acima citados de tensionamento dos limites da sexualidade proporcionam a ratificação do valor do consentimento para a experimentação do que seria a boa sexualidade, oposta à violência. Entretanto, se o prazer sexual se afirma diante da negação do consentimento ou da presença de vulnerabilidade que impeça a capacidade para consentir, ou seja, se é a violência que instiga o prazer, adentra-se num terreno em que os limites da sexualidade se esgarçam e, mais evidentemente, a violência é conotada, segundo Gregori, como "atos abusivos passíveis de condenação moral, social e de criminalização" (2008, p. 576).

A suspeita da presença de prazer na violência é dimensão relevante das imagens de brutalidade mobilizadas nas narrativas a respeito do "caso do serial killer de travestis" e da violência sofrida por Lua naquela noite de seresta. Nelas, a suspeita de prazer é catalizadora da brutalização. Como dito, a cena de violência contra Lua somente se dá após a recusa da cantada. Trata-se de uma vingança, um revide, uma resposta, uma punição, portanto. $O$ seu roteiro, porém, sugere o prazer através da performatização de um rebaixamento que alcança seu clímax quando os dois disparos de arma de fogo acontecem. O policial fardado sexualiza o ato de violência. É que, como contou Lua, o policial "escolheu o canto pra atirar", mas antes de desferir os tiros "fez todo um terrorismo comigo". Este terrorismo corresponde a uma ritualização erótica da produção do medo, da hierarquia e da humilhação. No que Lua me diz, afinal, o policial não a levou fardado para trás do bar e a alvejou simplesmente - o que já poderia ser tido como brutal. Ele fez mais: "começou a rasgar minha roupa, eu comecei a gritar, ele colocou um cano da arma no buraco do meu nariz, queria colocar na minha boca, passou por aqui e foi descendo, esfregou no meu peito ainda”.

Aqui, as roupas rasgadas sugerem de antemão violência sexual. Enquanto eu a escutava na sala do Espaço LGBT em João Pessoa, cheguei a imaginar que Lua 
me narraria uma cena de estupro. Depois, no entanto, o desnudamento arbitrário abre espaço para o exercício de uma liturgia em que o trânsito da arma - ou do falo - pelo corpo, penetrando alguns dos seus orifícios, submete o outro, rebaixa-o, humilha-o. Tudo isso antecede a tentativa de homicídio que se inicia com os dois tiros nas pernas e, de acordo com Lua, só não se completa porque aquela moça se joga sobre ela e a protege, levando-a para dentro do banheiro. De toda sorte, o que me interessa destacar é que as fronteiras entre violência sexual e violência letal são, nos relatos de Lua, bastante imprecisas, o que de certo modo deriva das marcas narrativas do rebaixamento e da humilhação - ou, nos termos de Díaz-Benítez (2015), das "práticas de humilhação extrema" - que insinuam prazer ao violentar. A prominência dessas práticas de humilhação nas narrativas de Lua me leva a considerar com gravidade a seguinte provocação, lançada por Díaz-Benítez (2015) em seus estudos sobre violência e erotismo:

Levando em conta que as novas formas de erotismo colocam o consentimento como base legítima para a realização e a legitimação das práticas e que muito do que se entende por direitos sexuais parte deste pressuposto, interessaria pensar na dupla prazer/violência para além da chave do consentimento? (Díaz-Benítez, 2015, p. 66).

Como expliquei anteriormente, minha aposta é a de que a insinuação do prazer é produtiva em narrativas de violência porque faculta a figuração do inaceitável, do absurdo ou do monstruoso, das imagens de brutalidade acionadas para a reivindicação de políticas de enfrentamento à violência, de justiça em determinados casos e de criminalização e punição de culpados. É isso o que ocorre nos autos judiciais sobre a morte de Suzanita, a suposta terceira vítima letal do " caso do serial killer de travestis”, como dito. Assim como nas narrativas de Lua sobre o episódio da seresta, essas narrativas documentais sugerem possíveis zonas de contato entre prazer e violência. Embora nada se diga nos autos judiciais sobre a ocorrência ou não de práticas sexuais entre Renato Humberto de França e suas vítimas, na denúncia que inaugura o processo criminal, o promotor de justiça infere que, como Renato Humberto era "frequentador assíduo daquele local" e "pessoa conhecida dos homossexuais que ali faziam seus programas", as vítimas eram "seduzidas" por ele "até o local onde seriam executadas". Penso que, por suas polissemias e ambiguidades, a palavra sedução empregada pelo promotor atua na compleição das citadas zonas de contato entre prazer e violência.

Argumentamos em outra ocasião que essa aparição narrativa da sedução pode insinuar erotismo, desejo e sexualidade, tal qual pode exprimir fraude (Efrem Filho, Souza Júnior e Leite, 2020). Estando o erotismo em questão, defrontamo-nos com a imagem de um assassino cuja sexualidade se relaciona às práticas dos crimes, tratando-se então de um "maníaco", aquele que, segundo Cilmara Veiga, compreende-se "numa interface relacional entre violência e gênero" (2018, p. 181). A seu tempo, estando a fraude sob questão, figura-se um sujeito maquiavélico, mas punível e responsável por seus atos, alguém absolutamente capaz de intencionar 
eliminar todas as raparigas, sapatões e viados da cidade de Carcarás. Esta ambiguidade entre erotismo e fraude pertinente a um "frequentador assíduo" de ruas onde travestis e homossexuais se prostituem recende, assim, às suspeitas sobre os desejos de Renato Humberto de França.

Isto porque a referida insinuação do prazer e da sedução acaba por ativar a ideia de desejo, incumbindo-o ao algoz. Os autos judiciais relativos à morte de Suzanita e os demais documentos públicos atinentes ao "caso do serial killer de travestis" potencializam dúvidas e suspeitas em torno da sexualidade do policial militar: afinal, Renato Humberto era "pessoa conhecida dos homossexuais que ali faziam seus programas" porque contratava esses programas?; ele seduzia suas vítimas porque as desejava sexualmente?; qual seria então a identidade sexual do policial militar Renato Humberto, esposo de Linalva de França, pai de três filhos?

Nas narrativas que rondam o caso, essas dúvidas quanto à sexualidade de Renato Humberto de França correlacionam-se a dúvidas quanto a quem são suas vítimas. Em parte das vezes, essas vítimas são genericamente identificadas como homossexuais. Noutras, são descritas como travestis ou como travestis e homossexuais. Além disso, embora todas as hipotéticas vítimas do serial killer atuassem na prostituição de rua, há situações narrativas em que a homossexuais e travestis acrescentam-se prostitutas - o que parece acontecer exatamente por conta de Suzanita, a única mulher cisgênera inserida entre as vítimas e não identificada como homossexual ou travesti. Logo, à exceção de Suzanita, as supostas vítimas do serial killer foram designadas como "do sexo masculino" em seus nascimentos e são frequentemente mencionadas, nos autos e demais documentos, por seus nomes masculinos de registro civil.

Naquele seminário de 23 de maio de 2017 no auditório da central de polícia, o delegado que conduziu as investigações do caso projetou sobre uma tela branca, posta diante da plateia, uma imagem com o que chamou de "linha do tempo" das mortes $^{12}$. Esta linha do tempo continha os nomes de registro e fotografias em preto e branco (sendo algumas delas cópias de documentos de identidade) das cinco vítimas fatais. Ao lado dos nomes de registro de quatro delas constavam, entre parênteses, “apelidos” ou "vulgos”, como normalmente se diz em delegacias, audiências e autos judiciais. Ao lado da figura do RG de Suzanita, por exemplo, havia "Suzana (Suzanita)". Em três das vítimas com nomes de registro masculinos havia outros nomes laterais, entres parênteses. Dois deles femininos, Lela e Lígia, um deles alusivo ao nome de um bombom muito conhecido na região, Xaxá - sendo assim, de gênero dúbio. Apenas a primeira vítima fatal, Alisson Marques, é apresentada unicamente com seu nome de registro.

A primeira impressão que tal confusão de nomes e identidades de gênero me causou, logo que entrei em contato com essas narrativas documentais, foi a de que delegado, promotor de justiça, policiais e jornalistas pouco ou nada conhecem dos repertórios comumente acionados na arena do movimento LGBTI+, nos setores de esquerda, no interior do campo de estudos de gênero e sexualidade e nas instâncias de Estado mais diretamente ligadas às políticas e à linguagem dos direitos humanos. Assim, nas narrativas implicadas no "caso do serial killer",
12 Segundo o delegado de polícia, as seis vítimas do serial killer de Carcarás seriam, em ordem: 01) Alisson Marques, morto em 14 de agosto de 2010; 02) Lela, morta em 4 de outubro de 2010; 03) Suzanita, morta em 21 de julho de 2011; 04) Edmundo, vítima de tentativa de homicídio em $1^{\circ}$ de setembro de 2011; 05) Lígia, morta em 16 de outubro de 2011; e 06) Xaxá, morta em 8 de dezembro de 2011. 
vítimas homossexuais, travestis e prostitutas terminam compondo uma massa indistinta, marcada pela vitimização e por um ou dois disparos de arma de fogo na base do crânio - a tal assinatura ${ }^{13}$. Ainda que essa minha primeira impressão se haja mantido, dada a sua verossimilhança, o contato mais próximo com as narrativas documentais e judiciais sobre mortes de LGBT tem-me oferecido diferentes perspectivas.

De regra, como notou Mariana Melo (2020) em pesquisa recente sobre homicídios de LGBT na Paraíba, a gestão estatal dessas mortes costuma demandar enquadramentos a respeito dessas violências que autorizam a agentes judiciais, policiais e governamentais a constituição de identidades e o controle de corpos. Sendo assim, conforme uma já vasta literatura tem afirmado, processos de reivindicação de direitos, lutas por justiça, legitimação de vítimas e punição de culpados tendem a requerer a confirmação de um sujeito de direitos vitimável, com identidade demarcada, normativa e moralmente (França, 2017; Efrem Filho, 2017a; Freire, 2016). Entretanto, no que venho observando em razão das atividades de pesquisa junto a processos judicias acerca de mortes de LGBT, essas narrativas judiciais constituem identidades e materializam corpos ao tempo que configuram cenários de delinquência e degeneração sexual, em que algozes e vítimas se confundem (Efrem Filho e Gomes, 2020; Efrem Filho, 2016). Isto se dá também nos documentos relativos ao "caso do serial killer de travestis", que parecem mimetizar aqueles cenários denunciados por Lua. Nesses documentos, as dúvidas sobre nomes, identidades de gênero e práticas sexuais de vítimas e algoz catalisam a degeneração.

\section{Violência, sexualidade e desejo}

Aqui precisamente aquilo que Fabiola me disse ao final do seminário de maio de 2017 tem lugar. "Professor, um caso assim deve ser muito interessante de analisar, não? O sujeito mata porque não se aceita. É terrível. É a homofobia internalizada”. Esta posição de Fabíola reproduz uma ideia corrente nas discussões sobre LGBTfobia, a de que a autoaversão e o sufocamento dos próprios desejos sexuais acarretariam práticas de discriminação, preconceito e violência contra alguém que encarna quem se seria de fato ou mesmo o objeto do desejo reprimido ${ }^{14}$. $\mathrm{O}$ que Fabiola anunciava no final daquela manhã, portanto, é que Renato Humberto de França era tão homossexual quanto suas vítimas, mas que a repulsa que sentia sobre si mesmo o conduzia à violência e, no limite, à figuração do serial killer. Fabíola atribuía narrativamente ao policial militar então um "nojo de si mesmo", uma emoção que implicaria o reconhecimento de que algo no corpo de quem a sente comporta a qualidade de nojento, mas cujas causas podem ser morais ou físicas, como explicou Díaz-Benítez (2019) ao tratar das narrativas de suas interlocutoras de pesquisa, ex-atrizes de filmes pornográficos, sobre si mesmas.

A atribuição ao serial killer de sentidos emocionais como os de aversão e autoaversão, repulsa e repulsa de si mesmo, nojo e nojo de si mesmo participa da constituição narrativa do algoz, como discuti no início deste texto. Serve, portanto,
13 Apenas o corpo de Lígia não apresentou perfuração na base do crânio, mas um tiro no tórax. Segundo o delegado explicou no seminário, essa diferença no modus operandi da morte levou-o inicialmente a não incluir Lígia entre as prováveis vítimas do serial killer Por isso, na denúncia acerca da morte de Suzanita, oferecida pelo promotor de justiça em abril de 2013, o nome de registro de Lígia não aparece. Outros elementos probatórios, como o horário e o local do homicídio e o que testemunhas haveriam dito, terminaram levando o delegado a mudar sua posição inicial e a inserir Lígia entre as vítimas.

14 Foge ao escopo deste artigo explorar detidamente os problemas dessa chave compreensiva. Importa notar, porém, que a noção de "homofobia internalizada" de regra circula no campo científico entre os saberes psi, do que a tese de doutorado em psicologia social de Antunes (2016) é um exemplo. 
à conflagração de uma personagem excepcional, porque monstruosa, capaz de empreender atos de violência também tidos como excepcionais, avessos à condição humana. Embora esse algoz opere sentidos nos autos judiciais e no "caso" de forma ampla, fornecendo culpado e causa para as mortes, sua fabulação vilanesca oculta os processos de Estado e as relações sociais muito desiguais que oportunizaram as mortes em Carcarás, assim como a trajetória de violência e humilhação narrada por Lua durante a nossa entrevista naquela tarde de julho de 2013, no Espaço LGBT.

As travestis e os homossexuais supostamente vitimados pelo serial killer partilhavam mais do que tiros desferidos na base do crânio e corpos deixados no Campo da Bagaceira. Tinham em comum experiências de classe, racialização, territorialização, geração, gênero e sexualidade bastante próximas, próximas inclusive àquelas descritas por Lua e vivenciadas por ela e outras monas anos atrás. Tais proximidades se exprimem, por exemplo, em suas dedicações à prostituição de rua nos centros de Carcarás ou João Pessoa, assim como em sua potencial exposição a experiências de violência, humilhação e criminalização. Nos interstícios dessas experiências, a transfobia e a homofobia não se explicam pela figura de um serial killer. Tampouco seriam elucidadas com a sua condenação, como de fato não foram.

Renato Humberto de França apenas foi condenado pela tentativa de homicídio contra $E d m u n d o^{15}$ e pelo cometimento de crime de posse ou porte ilegal de arma de fogo de uso restrito ${ }^{16}$. Nos autos dos processos judiciais relativos às mortes de Alisson Marques, Lela, Lígia e Xaxá, o magistrado proferiu sentença de impronúncia, provavelmente segundo a alegação de inexistência de "indícios suficientes de autoria", o que significa que Renato Humberto sequer foi levado a julgamento pelo tribunal do júri. Enquanto finalizo este texto, em janeiro de 2021, o processo judicial referente à morte de Suzanita ainda se acha em aberto. Como dito, Suzanita morreu em 21 de julho de 2011, há quase uma década, portanto. Como se vê, as decisões judiciais se opuseram à demarcação do serial killer. A condenação por uma tentativa de homicídio, afinal, não consubstancia um "assassino em série".

No entanto, a excepcionalização narrativa do serial killer e a hipótese levantada por Fabiola de que a causa para a violência estaria numa sexualidade frustrada são muitíssimo controversas no mínimo por mais uma razão. Além de ocultarem as desigualdades sociais e os processos de Estado que ensejam as condições de vulnerabilidade; além de sua aparente insuficiência para convencer determinado juiz; elas adjudicam à homossexualidade a origem de todo mal e se perdem nos limites da sexualidade, ratificando a inadmissibilidade da associação entre violência, prazer e desejo. Quero com isso dizer, de antemão, que identificar o germe de atos de violência numa sexualidade frustrada ou no "nojo de si mesmo" acaba por transferir para a própria homossexualidade - a que se teria aversão, repulsa etc. - a causa da violência. No fim, trata-se da reprodução da compreensão do homossexual como um sujeito absolutamente explicável a partir de sua sexualidade, inimaginável aquém ou além dela, como apontou Foucault (2010) ao se referir ao modo como os saberes médicos criaram e disciplinaram a identidade homossexual.
15 Com pena de 10 anos de reclusão em razão da tentativa de homicídio duplamente qualificado. A decisão dos jurados foi confirmada pelos desembargadores do Tribunal de Justiça da Paraíba.

16 Em 8 de fevereiro de 2012, policiais adentraram a casa de Renato Humberto de França, com vistas ao cumprindo de um mandado de busca e apreensão, e encontraram em seu quarto, na gaveta de uma cômoda, acessórios e munição de uso restrito que o policial não era autorizado a possuir. Com ele, no momento de sua prisão, também foi apreendida uma arma de fogo. O crime em questão está previsto no art. 16 da Lei 10.826, de 2003. 
Ainda que, hipoteticamente, as suspeitas e dúvidas lançadas nos autos judiciais acerca de sua sexualidade fossem sanadas, ainda que Renato Humberto de França viesse a público e "saísse do armário", admitindo uma homossexualidade até então escondida ou vivenciada clandestinamente no Campo da Bagaceira, imputar a causa dos atos de violência a uma homossexualidade frustrada - pela tal "homofobia internalizada" ou pelo o que quer que seja - pressupõe a incapacidade moral (e política) de admitir que pessoas podem desejar a violência, a humilhação, o rebaixamento do outro, querê-los e regozijar-se com eles. Além disso, pressupõe a incapacidade política (e moral) de reconhecer que práticas e agentes de Estado operam rotineiramente violências e humilhações através de uma linguagem de gênero e sexualidade. $O$ desejo e o prazer pela violência e pelo rebaixamento são, afinal, dimensões daqueles processos de Estado e relações de desigualdade e dos modos como os sujeitos se constituem enquanto os experienciam e produzem. Não são naturais do humano, de certo, mas compõem-no por meio de hierarquias sociais que, se implicam em violência e opressão, precisam ser enfrentadas. É isto, afinal, que militantes do movimento LGBTI+ fazem ao acionar a palavra LGBTfobia e elaborar relatórios em que os nomes de suas vítimas são listados. Movendo-se entre contradições, evocam imagens de brutalidade para combater a violência, para que ela não se repita. 


\section{Referências}

AGUIÃO, Sílvia. "Não somos um simples conjunto de letrinhas": disputas internas e (re) arranjos da política “LGBT”. Cadernos Pagu, n. 46, p. 279 - 310, 2016.

ANTUNES, Pedro Paulo Sammarco. Homofobia internalizada: o preconceito do homossexual contra si mesmo. Tese (Doutorado em Psicologia Social) - Pontifícia Universidade Católica de São Paulo - PUC-SP, São Paulo, 2016.

BARBOSA, Bruno César. "Doidas" e "putas": usos das categorias travesti e transexual. Sexualidad, Salud y Sociedad - Revista Latinoamericana, n. 14, p. 352 - 379, 2013.

BUTLER, Judith. Marcos de guerra: las vidas lloradas. Buenos Aires: Paidós, 2010.

CARDOSO DE OLIVEIRA, Luís Roberto. Existe violência sem agressão moral? Revista Brasileira de Ciências Sociais, v. 23, n. 67, p. 135 - 146, 2008.

CARVALHO, Mario Felipe de Lima. "Travesti”, "mulher transexual”, "homem trans" e "não binário": Interseccionalidades de classe e geração na produção de identidades políticas. Cadernos Pagu, n. 52, e185211, 2018.

COELHO, Maria Claudia. Narrativas da violência: a dimensão micropolítica das emoções. Mana, v. 16, p. 1 - 20, 2010.

CORRÊA, Mariza. Morte em família: representações jurídicas de papéis sexuais. Rio de Janeiro: Edições Graal, 1983.

DÍAZ-BENÍTEZ, María Elvira. O espetáculo da humilhação, fissuras e limites da sexualidade. Mana, v. 21, n. 1, p. 65 - 90, 2015.

DÍAZ-BENÍTEZ, María Elvira. O gênero da humilhação: afetos, relações e complexos emocionais. Horizontes Antropológicos, ano 25, n. 54, p. 51 - 78, 2019.

DÍAZ-BENÍTEZ, María Elvira. Sexo com animais como prática extrema do pornô bizarro. Cadernos Pagu, n. 38, p. 241 - 279, 2012.

EFREM FILHO, Roberto. Corpos brutalizados: conflitos e materializações nas mortes de LGBT. Cadernos Pagu, n. 46, p. 311 - 340, 2016.

EFREM FILHO, Roberto. Mata-mata: reciprocidades constitutivas entre classe, gênero, sexualidade e território. Tese (Doutorado em Ciências Sociais) - Universidade Estadual de Campinas - Unicamp, 2017a.

EFREM FILHO, Roberto. Os meninos de Rosa: sobre vítimas e algozes, crime e violência, Cadernos Pagu, n. 51, e175106, 2017b.

EFREM FILHO, Roberto; GOMES, José Clayton Murilo Cavalcanti. Homossexual, sapatão, travesti, traficante, viciada: gênero, sexualidade e crime em narrativas judiciais sobre mortes de LGBT. In: FACCHINI, Regina; FRANÇA, Isadora Lins. Direitos em disputa: LGBTI+, poder e diferença no Brasil contemporâneo. Campinas: Editora da Unicamp, 2020. p. $241-257$.

EFREM FILHO, Roberto; SOUZA JÚNIOR, Ailton Medeiros de; LEITE, Luís Erirrane Batista. O serial killer de travestis: sobre criminalização, gênero e sexualidade. In: GARCIA, Renata Monteiro et al. Sistema de Justiça Criminal e gênero: diálogos entre as criminologias crítica e feminista. João Pessoa: Editora do CCTA, 2020. p. 183 - 215.

FACCHINI, Regina. Entre umas e outras: mulheres, (homo)sexualidades e diferenças na cidade de São Paulo. Tese (Doutorado em Ciências Sociais) - Universidade Estadual de Campinas - Unicamp, Campinas, 2008. 
FACCHINI, Regina. Sopa de letrinhas?: movimento homossexual e produção de identidades coletivas nos anos 90. Rio de Janeiro: Garamond, 2005.

FACCHINI, Regina; MACHADO, Sara Rossetti. "Praticamos SM, repudiamos agressão": classificações, redes e organização comunitária em torno do BDSM no contexto brasileiro. Sexualidad, Salud y Sociedad - Revista Latinoamericana, n. 14, p. 195 - 228, 2013.

FERREIRA, Letícia Carvalho de Mesquita. “Apenas preencher papel”: reflexões sobre registros policiais de desaparecimento de pessoa e outros documentos. Mana, v. 19, n. 1, p. $39-68,2013$.

FONSECA, Claudia. A dupla carreira da mulher prostituta. Revista Estudos Feministas, n. 1, p. $7-33,1996$.

FOUCAULT, Michel. História da sexualidade l: a vontade de saber. Trad. Maria Theresa da Costa Albuquerque e J. A. Guilhon Albuquerque. São Paulo: Graal, 2010.

FRANÇA, Isadora Lins. "Refugiados LGBTI": direitos e narrativas entrecruzando gênero, sexualidade e violência. Cadernos Pagu, n. 50, e17506, 2017.

FREIRE, Lucas. Sujeitos de papel: sobre a materialização de pessoas transexuais e a regulação do acesso a direitos. Cadernos Pagu, n. 48, e164813, 2016.

GREGORI, Maria Filomena. Cenas e queixas: um estudo sobre mulheres, relações violentas e prática feminista. Rio de Janeiro: Paz e Terra; São Paulo: Anpocs, 1993.

GREGORI, Maria Filomena. Limites da sexualidade: violência, gênero e erotismo. Revista de Antropologia, v. 51, n. 2, p. 575 - 606, 2008.

GREGORI, Maria Filomena. Prazeres perigosos: erotismo, gênero e limites da sexualidade. São Paulo: Companhia das Letras, 2016.

LEITE JR., Jorge. Nossos corpos também mudam: a invenção das categorias "travesti” e "transexual" no discurso científico. São Paulo: Annablume, 2011.

LOWENKRON, Laura. Consentimento e vulnerabilidade: alguns cruzamentos entre o abuso sexual infantil e o tráfico de pessoas para fim de exploração sexual. Cadernos Pagu, n. 45, p. 225 - 258, 2015.

MCCLINTOCK, Anne. Couro imperial: raça, gênero e sexualidade no embate colonial. Trad. Plínio Dentzien. Campinas: Editora da Unicamp, 2010.

MELLO, Breno Marques de. Na selva de pedras: as performances de gênero e sexualidade no conflitos entre prostituição, crime e Estado. Dissertação (Mestrado em Ciências Jurídicas) - Universidade Federal da Paraíba - UFPB, 2019.

MELLO, Breno Marques de. Vestida para matar: fetiche e desejo na violência policial contra prostitutas. Monografia (Trabalho de Conclusão de Curso em Direito) - Universidade Federal da Paraíba - UFPB, 2016.

MELO, Mariana Soares Pires. Corpo, violência e Estado: percepções de operadores do sistema de justiça criminal acerca do homicídio de pessoas LGBTQI+. Tese (Doutorado em Sociologia) - Universidade Federal da Paraíba - UFPB, 2020.

MILLER, William Ian. The anatomy of disgust. Cambridge: Cambridge University Press, 1997.

MISSE, Michel. Crime, sujeito e sujeição criminal: aspectos de uma contribuição analítica sobre a categoria bandido. Lua Nova, n. 79, p. 15 - 38, 2010.

NADAI, Larissa. Entre estupros e convenções narrativas: os Cartórios Policiais e seus papéis numa Delegacia de Defesa da Mulher (DDM). Horizontes Antropológicos, ano 
22, n. 46, p. 65 - 96, 2016.

OLIVAR, José Miguel Nieto. Prostituição feminina e direitos sexuais... Diálogos possíveis? Sexualidad, Salud y Sociedad - Revista Latinoamericana, n. 11, p. 88 - 121, 2012.

RANGEL, Everton. Depois do estupro: homens condenados e seus tecidos relacionais. Tese (Doutorado em Antropologia Social) - Museu Nacional; Universidade Federal do Rio de Janeiro - UFRJ, Rio de Janeiro, 2020.

SIMIÃO, Daniel Schroeter. Representando corpo e violência: a invenção da "violência doméstica" em Timor-Leste. Revista Brasileira de Ciências Sociais, v. 21, n. 60, p. 135 $-146,2006$.

VEIGA, Cilmara. O caso do maníaco matador de velhinhas: entre trâmites processuais e diferentes formas de narrar que enredam um crime em série. Dissertação (Mestrado em Antropologia Social) - Universidade Estadual de Campinas - Unicamp, Campinas, 2018.

VIANNA, Adriana; FARIAS, Juliana. A guerra das mães: dor e política em situações de violência institucional. Cadernos Pagu, n. 37, p. 79-116, 2011.

VIANNA, Adriana; LOWENKRON, Laura. O duplo fazer do gênero e do Estado: interconexões, materialidades e linguagens. Cadernos Pagu, n. 51, e175101, 2017. 